\title{
Olanzapine produced a higher clinical response rate than risperidone in schizophrenia
}

Tran PV,Hamilton SH, Kuntz AJ, et al. Double-blind comparison of olanzapine versus risperidone in the treatment of schizophrenia and other psychotic disorders.J Clin Psychopharmacol 1997 Oct;17:407-18.

\section{Objective}

To compare the effectiveness of olanzapine and risperidone in patients with schizophrenia.

\section{Design}

28 week randomised, double blind, controlled trial.

\section{Setting}

35 centres in 9 countries ( 8 in Europe, 1 in North America).

\section{Patients}

339 patients who were 18 to 65 years of age (mean age 36 y, $65 \%$ men) and met the Diagnostic and Statistical Manual of Mental Disorders, 4th edition criteria for schizophrenia, schizophreniform disorder, or schizoaffective disorder, and had a minimum score of $\geqslant 42$ on the Brief Psychiatric Rating Scale. Exclusion criteria were comorbid or recent major axis I disorder, serious medical illness, pregnancy or lactation, or lack of at least minimal clinical response with $\geqslant 3$ antipsychotic drugs in 3 chemical classes. 53\% of patients completed the study.

\section{Intervention}

Patients were allocated to olanzapine, 10 to $20 \mathrm{mg}$ /day ( $\mathrm{n}=172)$, or risperidone, 4 to $12 \mathrm{mg} /$ day $(\mathrm{n}=167)$. Titration of dosages was permitted to optimise patient outcome.

\section{Main outcome measures}

Change in total score on the Positive and Negative Syndrome Scale (PANSS), response rate, and adverse effects.

\section{Main results}

Analysis was by intention to treat. Compliance rates were similar for olanzapine and risperidone groups (84.1\% v 81.8\%). Patients in olanzapine and risperidone treated groups improved from baseline with mean decreases in PANSS total score of 28.1 and
24.9 , respectively ( $\mathrm{p}<0.001$ for both). Olanzapine produced greater improvement in the Scale for the Assessment of Negative Symptoms summary score (mean decrease of 4.3) than risperidone (mean decrease of 2.9$) \quad(\{95 \%$ CI for the 1.4 difference 0.4 to 2.4$\}^{*}, \mathrm{p}=0.02$ ). More patients treated with olanzapine than risperidone were responders $(\mathrm{p}=0.049)$ (table). Olanzapine treated patients had greater improvement in mood (PANSS depression item) than did risperidone treated patients (mean change $-1.1 v-0.7, \mathrm{p}=0.004$ ). Fewer patients who received olanzapine had any extrapyramidal side effects (EPS) than did patients who received risperidone $(18.6 \%$ v $31.1 \%$, $\mathrm{p}=0.008)$. Greater weight gain occurred in olanzapine treated patients $(4.1 \mathrm{~kg})$ than in risperidone treated patients $(2.3 \mathrm{~kg})(\{\mathrm{CI}$ for the $1.8 \mathrm{~kg}$ difference 0.6 to 3.0$\}^{*}, \mathrm{p}=0.015$ ). Fewer olanzapine treated patients had raised prolactin concentrations than did risperidone treated patients $(51 \% v 94 \%, \mathrm{p}<0.001)$.

\section{Conclusion}

Olanzapine achieved a greater response rate than risperidone in schizophrenia with fewer extrapyramidal side effects.

*Numbers calculated from data in article.

Response rates for olanzapine $v$ risperidone $\dagger$

\begin{tabular}{|c|c|c|c|c|c|}
\hline Outcome at 28 weeks & $\begin{array}{l}\text { Olanzapine } \\
\text { EER }\end{array}$ & $\begin{array}{l}\text { Risperidone } \\
\text { CER }\end{array}$ & 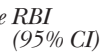 & $\begin{array}{l}A B I \\
|E E R-C E R|\end{array}$ & $\begin{array}{l}\text { NNT } \\
(C I)\end{array}$ \\
\hline $\begin{array}{l}\geqslant 40 \% \text { improvement } \\
\text { in PANSS total } \\
\text { score }\end{array}$ & $36.8 \%$ & $26.7 \%$ & $\begin{array}{l}37.8 \% \\
(0.17 \text { to } \\
90.6)\end{array}$ & $10.1 \%$ & $\begin{array}{l}10 \\
(5 \text { to } \\
1881)\end{array}$ \\
\hline
\end{tabular}

$\nmid$ PANSS $=$ Positive and Negative Syndrome Scale. Other abbreviations defined in glossary; RBI, ABI, NNT,and CI calculated from data in article

Source of funding: Lilly Research Laboratories.

For article reprint:Dr P V Tran, Lilly Research Laboratories, Eli Lilly and Company, Lilly Corporate Center, Drop Code 0538, Indianapolis, IN 46285, USA. Fax +1 3172776896.

\section{Commentary}

One bonus resulting from the introduction of new antipsychotic drugs is the renewed interest in doing comparative studies, of which this study by Tran et al is a useful example. A problem in these studies, however, is the difficulty in ensuring that the drug doses are comparable. The doses used in this study do not reflect the recent decrease in the recommended dose of risperidone. Although risperidone may be less "typical" than standard antipsychotic drugs, it is clearly less "atypical" than the benchmark clozapine because its use is associated with dose dependent increases in EPS and prolactin secretion. ${ }^{1}$ Half of the observations in this study are therefore not surprising.

One of the key findings was that olanzapine was more effective in reducing negative features of schizophrenia, an effect attributed to an action on "primary" symptomatology-potentially a very im- portant finding indeed. Alas, psychiatry's efforts in conceptualising the boundaries of schizophrenic "negativity" have not been matched by similar rigour in defining the boundaries of extrapyramidal symptomatology. These complex disorders have been conceptualised within an almost exclusively sign led framework. The SimpsonAngus scale, used here to evaluate parkinsonism, is inadequate to address the most important question: whether risperidone and olanzapine have a differential effect on the signs and symptoms of bradykinesia. The major advantage which the authors attribute to olanzapine might well reflect tolerability rather than efficacy. Such an advantage would still represent important and clinically useful information, if the doses were comparable. But are they?

The authors refer to the increasing use of path analysis as a technique for separating the components of change in schizophrenic "negativity" but application of such sophisticated methodology to "rater subjective" data tells us only where the rater thought the balance of change lay rather than where it actually lay.

The favourable tolerability of olanzapine and the dose dependent liability to EPS of risperidone confirm clinical impression. It is doubtful if this study can tell us more. The low dose risperidone comparison is no doubt already being planned.

David G Cunningham Owens MD (Hons), FRCP, FRCPysch University of Edinburgh Edinburgh, UK

1 Owens DG. J Clin Psychiatry 1994;55:29-35.

\section{Author's response}

Regarding the dose of risperidone used in the study, this is a long term study (28 wk) and there is a lack of evidence to show that doses of risperidone $\leqslant 6 \mathrm{mg} /$ day are effective in maintenance treatment. 